\title{
ETHIOPIAN NATURAL ZEOLITES FOR PHOTOCATALYSIS
}

\author{
Kiros Guesh ${ }^{1,2}$, María José López-Muñoz ${ }^{3}$, Carlos Márquez-Álvarez ${ }^{4}$, Yonas Chebude ${ }^{1}$ and \\ Isabel Diaz ${ }^{1,4^{*}}$ \\ ${ }^{1}$ ChemistryDepartment, Addis Ababa University, Addis Ababa, Ethiopia \\ ${ }^{2}$ Mizan-Tepi University, Mizan-Teferi, Ethiopia \\ ${ }^{3}$ Department of Chemical and Environmental Technology, ESCET, Universidad Rey Juan \\ Carlos, C/Tulipán s/n, 28933 Móstoles, Madrid, Spain \\ ${ }^{4}$ Instituto de Catálisis y Petroleoquímica, CSIC, C/Marie Curie 2, 28049 Madrid, Spain
}

(Received January 7, 2015; revised August 25, 2015)

\begin{abstract}
The combination of zeolites and photochemistry has recently shown excellent results due to the special structure of the zeolites that helps a better use of the solar energy improving the selectivity of the chemical reactions carried out. There are several reports on the preparation of $\mathrm{TiO}_{2}$ confined nanoparticles in synthetic zeolites. However, very few reports are found on the use of natural zeolites. Zeolites are a vast natural resource in Ethiopia that remains unexploited. Their microporous structure can accommodate a wide variety of cations such as sodium, potassium and magnesium among others. The main objective of our work was to test the potential use of the naturally occurring zeolites, with high content in titanium, as photocatalysts. The samples have been characterized by X-ray diffraction (XRD), chemical analysis (ICP-OES), scanning electron microscopy (SEM), diffuse reflectance spectroscopy (UV-Vis) and photocatalytic activities of the samples were tested in photocatalytic degradation of methyl orange (MO).
\end{abstract}

KEY WORDS: Natural zeolite, Photocatalysis, Band gap energy, Methyl orange, $\mathrm{TiO}_{2}$ loading

\section{INTRODUCTION}

Due to the increasingly polluted environment and the gradual depletion of fossil fuel reserves, the development of renewable technologies for environmental remediation, environmental sustainability and energy production is highly desirable. Semiconductor based heterogeneous photocatalysis is a promising means to alleviate the problems [1]. The photocatalysis research area has been interesting to the scientific community since 1972 when Fujuma and Honda [2] observed electrochemical photolysis of water on $\mathrm{TiO}_{2}$ semiconductor electrode. Since then, different developments have been witnessed and the arena of this research area became widespread among chemical engineers, materials scientists, physicists, chemists and environmental scientists. Its application nowadays includes photocatalytic environmental treatment, photochemical synthesis and water splitting for energy purpose. Of the many tested photocatalysts, $\mathrm{TiO}_{2}$ is found to be superb owing to its higher photocatalytic activity, suitable band position, reasonable price and photostability [3-7]. However, $\mathrm{TiO}_{2}$ shows drawbacks such as narrow excitation wavelength and/or large band gap [8-10], fast recombination rate of photogenerated electron-hole pairs $[2,8-10]$ relatively poor adsorption capacity $[8,11,12]$, and difficulties in recycling (recovering) $[11,13]$. In addition, recent researches are indicating that the $\mathrm{TiO}_{2}$ in the nanosized regime can be toxic in high concentration [14]. Thus, efforts should be devoted to preventing the leakage of $\mathrm{TiO}_{2}$ to the environment during application. Among the various supports that are potentially available, zeolites have been most favorable to be used in supporting $\mathrm{TiO}_{2}$, due to their photochemical stability, transparency to UV-Visible radiation above $240 \mathrm{~nm}$ wavelength, unique structures, uniform pores and channels, which leads to large surface area and synergetic adsorption effects of organic matter $[11,12]$. In the past few years, new attempts to locate zeolite deposits in Ethiopia have yielded several interesting phases [15]. Among them, there is at least one area with a natural zeolite (Mordenite) containing high

\footnotetext{
*Corresponding author. E-mail: idiaz@icp.csic.es
} 
concentration of titanium. This sample, called ET4, contains other non-zeolitic phases like celadonite and ilmenite, which may synergize the potential application of this high Ticontainingsample for photocatalysis.

\section{Sample preparation}

\section{EXPERIMENTAL}

Three different approaches were carried out: i) simple calcination of raw zeolite ET4 sample: 1 $\mathrm{g}$ of natural zeolite (ET4) was calcined in air for $3 \mathrm{~h}$ at $300,400,500$ and $600{ }^{\circ} \mathrm{C}$ at a rate of 3 ${ }^{\circ} \mathrm{C} / \mathrm{min}$. The resulting samples were labeled as ET4-300, ET4-400, ET4-500 and ET4-600 respectively. ii) Loading of raw zeolite ET4 samplewith $20 \% \mathrm{TiO}_{2}$ followed by calcination at $500{ }^{\circ} \mathrm{C}$, labeled 20TET4-500: $1.6 \mathrm{~g}$ of ET4 is suspended in a solution of $2.01 \mathrm{~mL}$ of titaniumbutoxide (Ti(OBut) $\left.)_{4}\right)$ dissolved in a mixture of 2-propanol $\left(\mathrm{CH}_{3} \mathrm{CHOHCH}_{3}\right)$ and water $\left(\mathrm{H}_{2} \mathrm{O}\right)$ with volume ratio of $1: 10: 2\left(\mathrm{Ti}(\mathrm{OBut})_{4}: \mathrm{CH}_{3} \mathrm{CHOHCH}_{3}: \mathrm{H}_{2} \mathrm{O}\right)$. The suspension was stirred at room temperature for $24 \mathrm{~h}$. The solvent was removed by rotary evaporator and dried at 110 ${ }^{\circ} \mathrm{C}$. The sample was then calcined in a furnace at $500{ }^{\circ} \mathrm{C}$ for $3 \mathrm{~h}$ at $3{ }^{\circ} \mathrm{C} / \mathrm{min}$. iii) Raw zeolite ET4 sample was treated following a recipe previously optimized in our laboratory [16], then loaded with $20 \% \mathrm{TiO}_{2}$ as described in (ii) followed by calcination at $500{ }^{\circ} \mathrm{C}$, labeled $20 \mathrm{TET} 4 \mathrm{t}-$ 500. For the treatment, $2 \mathrm{~g}$ of ET4 was stirred in $26 \mathrm{~mL}$ of $3 \mathrm{M} \mathrm{CH}_{3} \mathrm{COONH}_{4}\left(\mathrm{NH}_{4} \mathrm{Ac}\right)$ at room temperature for $30 \mathrm{~min}$. Then $12 \mathrm{~mL}$ of aqueous solution of $2.4 \mathrm{M} \mathrm{NH}_{4} \mathrm{~F}$ was added drop wise at $80{ }^{\circ} \mathrm{C}$ under magnetic stirring. The suspension was stirred for $30 \mathrm{~min}$. The sample is then filtered and washed with distilled water, dried at $100{ }^{\circ} \mathrm{C}$ for $12 \mathrm{~h}$. After this it is calcined at 550 ${ }^{\circ} \mathrm{C}$ for $6 \mathrm{~h}$ at rate of $3{ }^{\circ} \mathrm{C} / \mathrm{min}$ and then loaded with $20 \% \mathrm{TiO}_{2}$ followed by calcination at $500{ }^{\circ} \mathrm{C}$.

\section{Sample characterization}

Powder X-ray diffraction (XRD) patterns were collected with X'Pert Pro PANalytical (CuK $\alpha$ radiation $=0.15406 \mathrm{~nm}$ ). Inductively coupled plasma optical emission spectrometry (ICP-OES) Optima 3300 DV model, was used to determine the chemical composition. Digestion of the samples was obtained by alkaline fusion in an automatic fusion in Teflon vessels. Two different scanning electron microscopes were used: Hitachi TM-100 and a FEI NOVA NANO SEM 230, both with backscattered electrons detector and EDX analysis. The UV-Vis diffuse reflectance UV-Vis spectroscopy (DRS) measurements were done using a Varian Cary 5000 double-beam UV-Vis-NIR spectrophotometer. Collected spectra were converted to Kubelka-Munk function, $\mathrm{F}(\mathrm{R})$ versus wavelength. The band gap of the samples was estimated using the Tauc plots.

\section{Photocatalytic test}

For a particular photocatalytic test, $0.5 \mathrm{~g}$ of sample was suspended in a ca. $10 \mathrm{ppm}$ aqueous solution of methyl orange (MO) in a $1 \mathrm{~L}$ borosilicate glass reactor equipped with borosilicate glass cooling pipe and ports for sample withdrawing and oxygen purging. The mixture was stirred for $15 \mathrm{~min}$ in continuous purging of air to maintain adsorption-desorption equilibrium of MO with the powder photocatalyst material. Then, the suspension was irradiated with a $150 \mathrm{~W}$ UV lamp (Heraeus medium pressure mercury lamp) and samples were withdrawn in time intervals for analysis after filtering out the photocatalyst.

\section{RESULTS AND DISCUSSION}

In our attempt to locate and analyze deposits of natural zeolites in Ethiopia [16], we have identified some phases that possess interesting chemical compositions that may lead to direct photocatalysis with very little modifications. Among the natural zeolites identified, sample ET4, a mixture of celadonite, ilmenite and mordenite (Figure 1) was selected for further photocatalytic applications due to the high content of Ti and Fe (Table 1). 


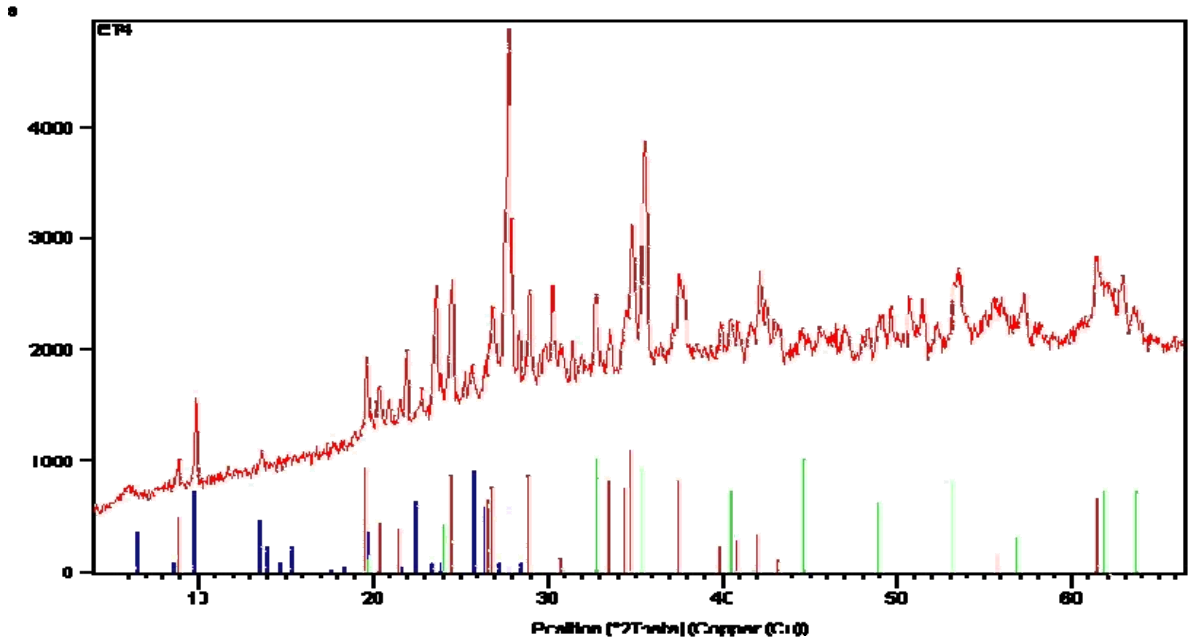

Figure 1. XRD profile where ET4 sample is identified as a mixture of Celadonite in red (00-0170521), Mordenite in blue (00-038-0318) and Ilmenite in green.

Table 1. ICP elemental analysis of Ethiopian natural zeolite ET4.

\begin{tabular}{|c|c|c|c|c|c|c|c|c|}
\hline Sample & $\begin{array}{c}\mathrm{Al} \\
(\% \mathrm{wt})\end{array}$ & $\begin{array}{c}\mathrm{Si} \\
(\% \mathrm{wt})\end{array}$ & $\begin{array}{c}\mathrm{Na} \\
(\% \mathrm{wt})\end{array}$ & $\begin{array}{c}\mathrm{K} \\
(\% \mathrm{wt})\end{array}$ & $\begin{array}{c}\mathrm{Ca} \\
(\% \mathrm{wt})\end{array}$ & $\begin{array}{c}\mathrm{Mg} \\
(\% \mathrm{wt})\end{array}$ & $\begin{array}{c}\mathrm{Fe} \\
(\% \mathrm{wt})\end{array}$ & $\begin{array}{c}\mathrm{Ti} \\
(\% \mathrm{wt})\end{array}$ \\
\hline ET4 & 3.6 & 22.9 & 1.3 & 3.6 & 1.8 & 1.1 & 10.2 & 3.5 \\
\hline
\end{tabular}
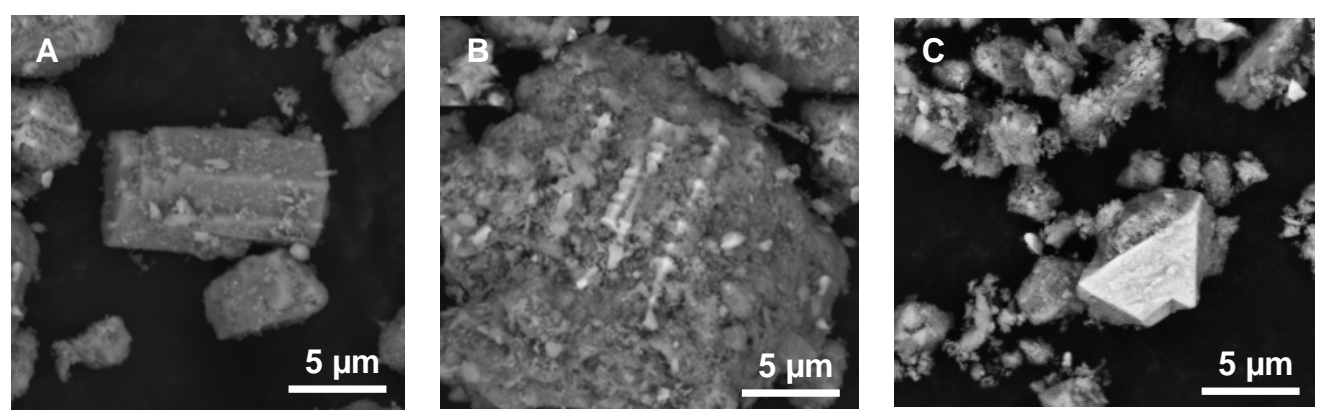

Figure 2. SEM micrographs of sample ET4 showing A) Mordenite, B) Celadonite and C) Ilmenite phases, identified by EDX.

The elemental composition reported in Table 1 yields a Si/Al molar ratio of 6.11 , a bit higher than that of natural mordenites, which varies between 4 and 6 $\left(\mathrm{Na}_{1.1} \mathrm{Ca}_{0.5} \mathrm{~K}_{0.1} \mathrm{Al}_{2.2} \mathrm{Si}_{9.8} \mathrm{O}_{24} \cdot 5.9\left(\mathrm{H}_{2} \mathrm{O}\right)\right.$ [17]. This difference must be due to a significant contribution of silicon provided by Celadonite $\left(\mathrm{KMg}_{0.8} \mathrm{Fe}^{2+}{ }_{0.2} \mathrm{Fe}^{3+}{ }_{0.9} \mathrm{Al}_{0.1} \mathrm{Si}_{4} \mathrm{O}_{10}(\mathrm{OH})_{2}\right)$, which is also responsible of larger amounts of $\mathrm{K}, \mathrm{Mg}$ and $\mathrm{Fe}$. Finally, the surprisingly high content on $\mathrm{Ti}$ is expected to be related to the Ilmenite phase $\left(\mathrm{FeTiO}_{3}\right)$, although the coexistence of $\mathrm{Ti}$ in the zeolitic Mordenite phase should not be discarded. 

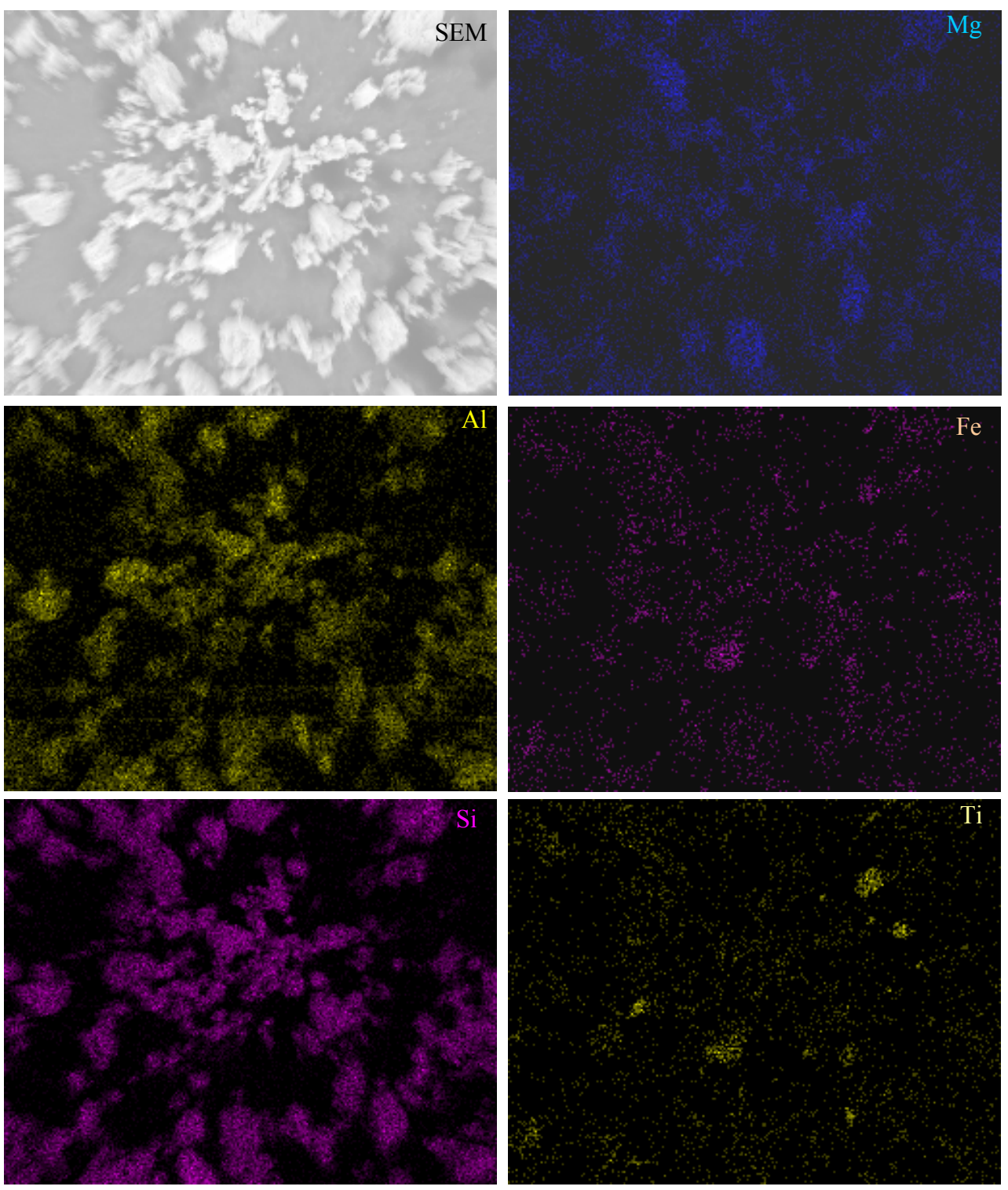

Figure 3. SEM/EDX Mapping of sample ET4.

In order to corroborate this distribution of elemental composition, ET4 sample was studied by scanning electron microscopy coupled with energy dispersive X-ray spectroscopy (SEMEDX). Figure 2 collects representative SEM micrographs of ET4 where the nice hexagonally shaped crystals of Mordenite could be observed (Figure 2A) along with larger shapeless particles identified as Celadonite (Figure 2B), and brighter particles (due to the higher atomic number) identified as Ilmenite (Figure 2C). 


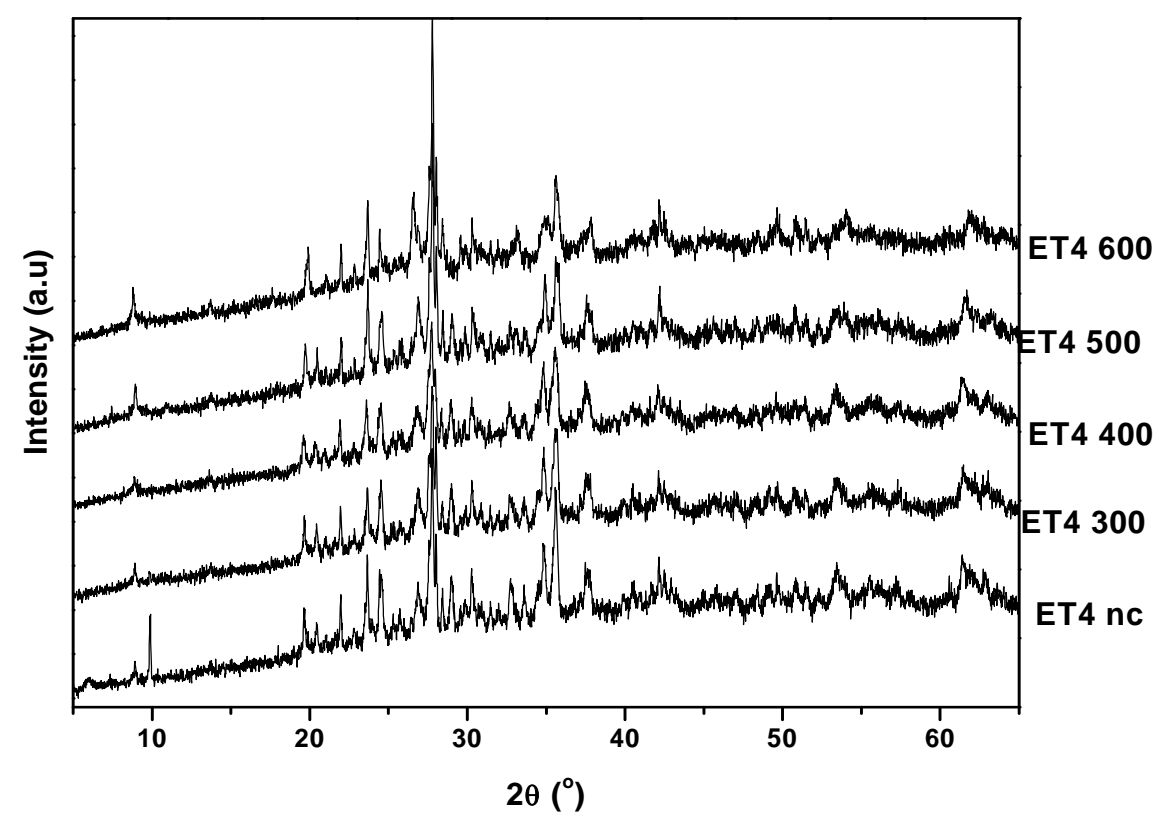

Figure 4. XRD patterns of ET4 not calcined (nc) and calcined at $300,400,500$ and $600{ }^{\circ} \mathrm{C}$.

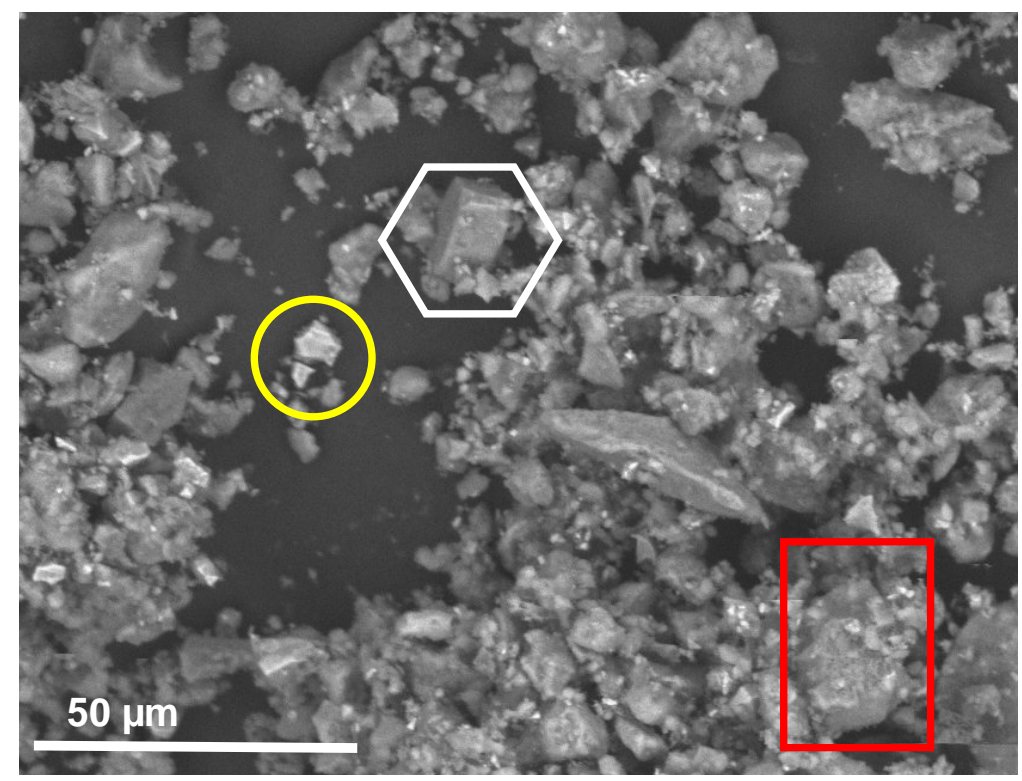

Figure 5. SEM micrograph of sample ET4 500 showing crystals of Mordenite (hexagon), Celadonite (rectangle) and Ilmenite (circle) phases, identified by their shape and EDX. 
There seems to be higher ratio of Celadonite than the rest of the phases, and more Ilmenite than in other zeolites samples collected in the same region. Nevertheless, what makes this sample interesting is that the phases with $\mathrm{Ti}$ also seem to be associated to some $\mathrm{Si}$.

The exhaustive SEM study coupled with EDX mapping (Figure 3) show that the particles with a higher amount of $\mathrm{Na}$ found by EDX could be richer in MOR and those with Mg could be richer in Celadonite. On the other hand, there are clearly Ilmenite particles always showing brighter contrast due to the higher atomic number with $\mathrm{Fe} / \mathrm{Ti}=1$ by $\mathrm{EDX}$, although the presence of Ti is also observed in Si-related particles as mentioned before.

Thus a range of calcination temperatures were tested to obtain the desired phases. The XRD pattern in Figure 4 confirm that the zeolite structure remains stable after calcination up to 600 ${ }^{\circ} \mathrm{C}$ showing no diffraction peaks of either rutile or anatase phases. This could be due to the small particle sizes obtained, in case the desired phases are obtained. The SEM analysis (Figure 5) of sample ET4 500 shows no presence of segregated phases of $\mathrm{TiO}_{2}$, while the three main phases of parent ET4 could be clearly observed concluding that the calcinations process has not inferred any morphological change to the natural zeolites.

As can be seen from the diffuse reflectance spectra of the samples calcined at different temperature (Figure 6) the absorption edge has been extended to wider wavelength with increasing calcination temperature. The absorption edge of ET4nc and ET4-300 were around $450 \mathrm{~nm}$. Upon further calcination the absorption edge for ET4-400 and ET4-500 is shifted to $521 \mathrm{~nm}$ and $560 \mathrm{~nm}$, respectively. However, further calcination to $600{ }^{\circ} \mathrm{C}$ does not bring a change in the absorption edge. Thus the shift of absorption edge from ET4nc to ET4-500 may be indicating that calcination within this temperature range provokes electronic modification on the samples. The band gap energy of these samples is estimated using Tauc plot by plotting theroot square ofthe product of the Kubelka-Munk function $(\mathrm{F}(\mathrm{R}))$ and photonenergy $(\mathrm{h} v)$ of diffuse-reflectance of each sample against energy. Accordingly, it was found that the band gap energy of the ET4nc, ET4-300, ET4-400, ET4-500 and ET4-600 become 2.63, 2.63, 2.21, 1.52, and $1.52 \mathrm{eV}$, respectively.

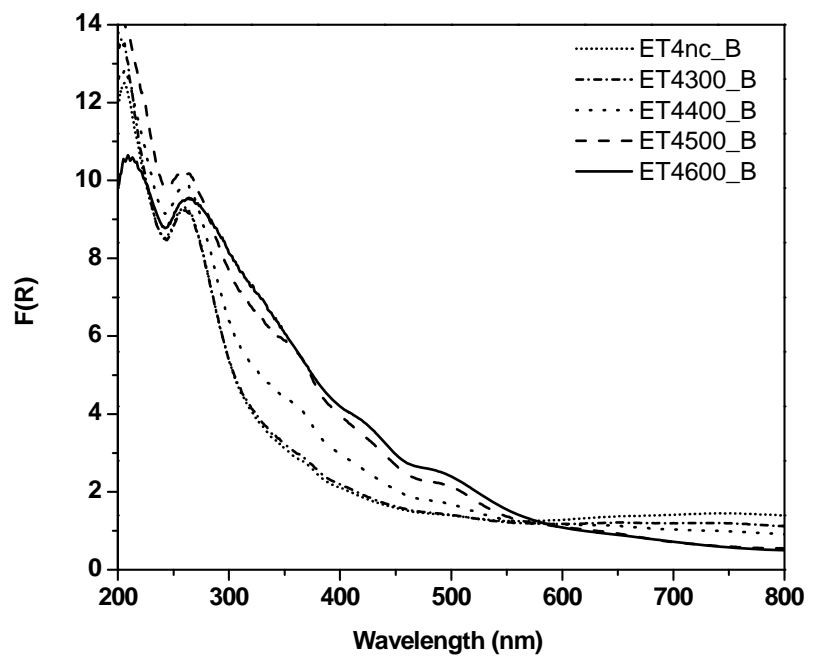

Figure 6. A) Diffuse reflectance spectra of ET4nc, and calcined at different temperatures. 
From the diffuse reflectance spectra, this particular natural zeolite could be a promising photocatalyst by calcination at $500{ }^{\circ} \mathrm{C}$. However, no significant photocatalytic activity was found, as it will be discussed later.

Further attempt was carried out in order to enhance the photocatalytic potential of the sample. Extra loading of $20 \% \mathrm{TiO}_{2}$ was included to ET4 yielding a material that contains $\mathrm{Ti}$ species potentially active for photocatalysis. However, the photocatalytic activity is very low. We presume that the reason behind this low activity is the presence of impurities that together to extra framework cations could deplete the path of the generated electrons and holes of the system, required for photocatalysis. Therefore, same $20 \% \mathrm{TiO}_{2}$ was loaded on ET4 sample that was previously treated to remove the impurities. The ICP results of these two samples (Table 2) indicate the exact same amount of $\mathrm{Ti}$ incorporated in both samples. However, the $\mathrm{TiO}_{2}$ loading procedure has led to a remarkable decrease in the content of Si in sample 20TET4-500 with a final $\mathrm{Si} / \mathrm{Al}$ ratio of 3.36. On the other hand, further treatment of ET4 sample with $\mathrm{NH}_{4} \mathrm{Ac}+$ $\mathrm{NH}_{4} \mathrm{~F}$ yields further decrease in the $\mathrm{Si}$ content with a final $\mathrm{Si} / \mathrm{Al}$ ratio 2.44.

Table 2. ICP Elemental Analysis of loaded ET4 samples untreated, 20TET4, and previously treated, 20TET4t, both calcined at $500{ }^{\circ} \mathrm{C}$.

\begin{tabular}{|l|c|c|c|c|c|c|c|c|}
\hline Sample & $\begin{array}{c}\mathrm{Al} \\
(\% \mathrm{wt})\end{array}$ & $\begin{array}{c}\mathrm{Si} \\
(\% \mathrm{wt})\end{array}$ & $\begin{array}{c}\mathrm{Na} \\
(\% \mathrm{wt})\end{array}$ & $\begin{array}{c}\mathrm{K} \\
(\% \mathrm{wt})\end{array}$ & $\begin{array}{c}\mathrm{Ca} \\
(\% \mathrm{wt})\end{array}$ & $\begin{array}{c}\mathrm{Mg} \\
(\% \mathrm{wt})\end{array}$ & $\begin{array}{c}\mathrm{Fe} \\
(\% \mathrm{wt})\end{array}$ & $\begin{array}{c}\mathrm{Ti} \\
(\% \mathrm{wt})\end{array}$ \\
\hline 20TET4-500 & 5.65 & 19.76 & 1.28 & 3.47 & 2.80 & 1.53 & 9.90 & 17.50 \\
\hline 20TET4t-500 & 8.22 & 20.90 & 1.40 & 3.78 & 2.99 & 1.67 & 9.84 & 17.00 \\
\hline
\end{tabular}

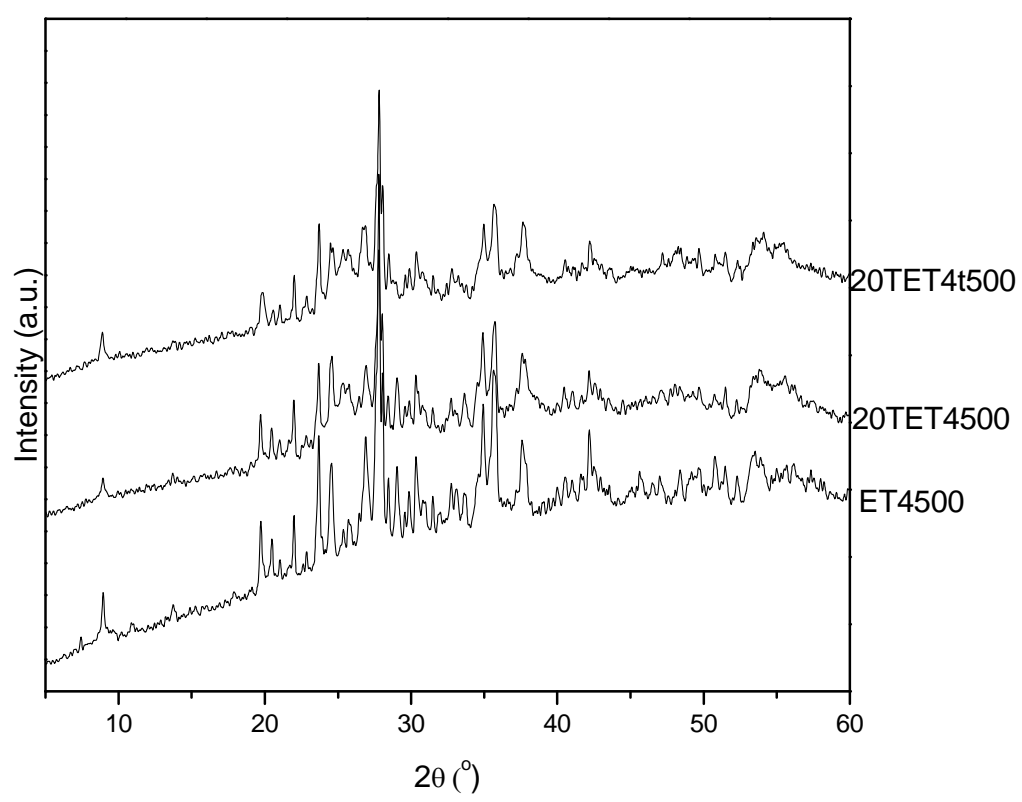

Figure 7. XRD profile of 20TET4t-500, 20TET4-500 and ET4-500.

The XRD profiles of these samples are plotted in Figure 7. The XRD patterns confirm that zeolite structure remains stable after treatment, loading $20 \% \mathrm{TiO}_{2}$ and calcination up to $500{ }^{\circ} \mathrm{C}$. 
Deeper search for evidences of the presence of $\mathrm{TiO}_{2}$ independent particles is difficult, since most of the diffraction intensities overlap with those of the natural zeolite.

The diffuse reflectance spectra (DRS) of these samples are plotted in Figure 8. It is evident that, as expected, incorporation of $\mathrm{TiO}_{2}$ led to a shift of the absorption edge and an increase of the area of absorption band for 20TET4-500 and 20TET4t-500 samples.

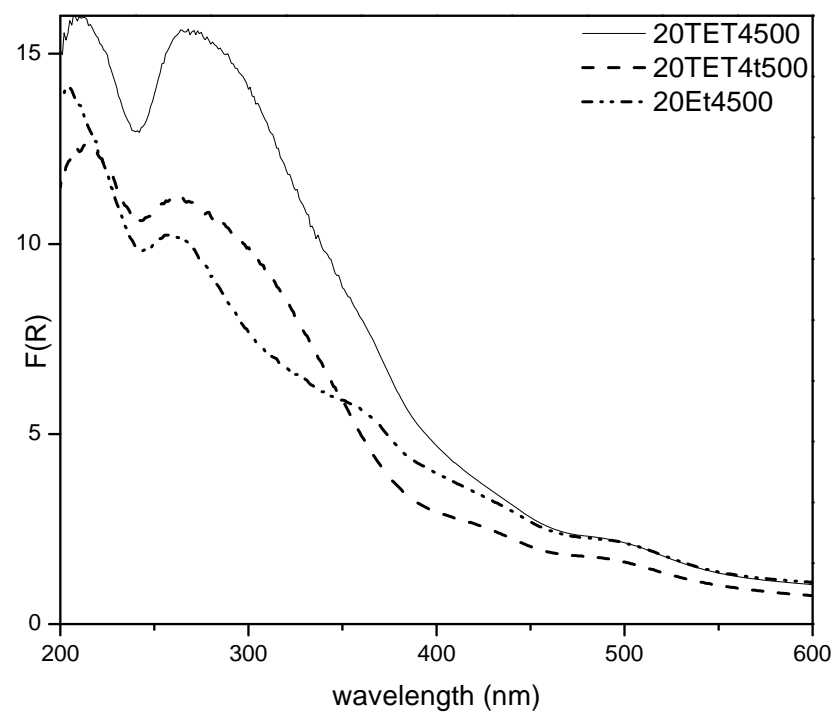

Figure 8. DRS of 20TET4t-500, 20TET4-500 and ET4-500.

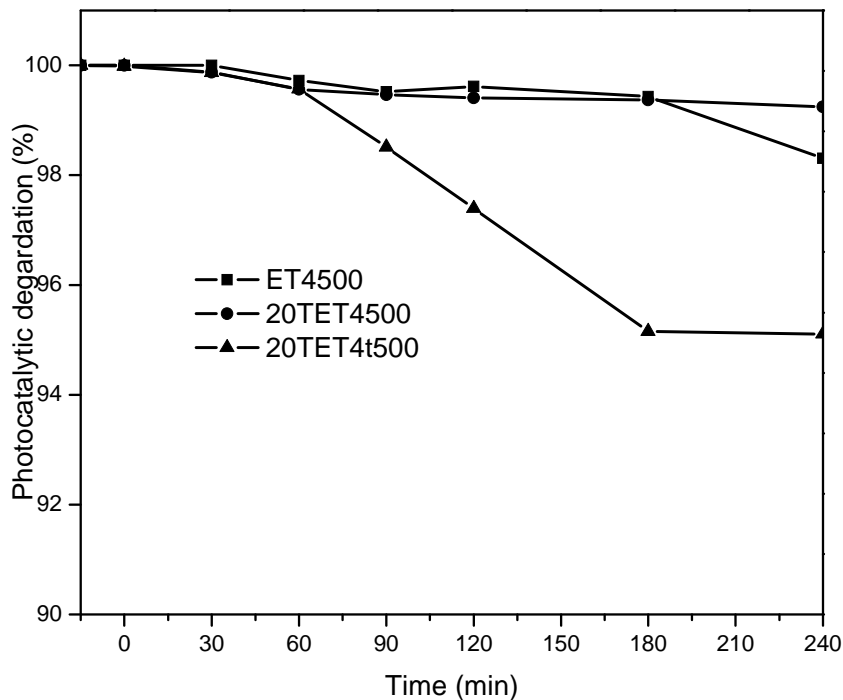

Figure 9. Photocatalytic degradation of 10 ppm MO 20TET4t-500, 20TET4-500 and ET4-500.

Bull. Chem. Soc. Ethiop. 2015, 29(3) 
The photocatalytic activity test of 20TET4t-500, 20TET4-500 and ET4-500 materials is summarized in Figure 9. The sample that has been treated before $\mathrm{TiO}_{2}$ loading (20TET4t-500) shows higher activity than 20TET4-500 and ET4-500 although it is still very low compared with that reported for pure $\mathrm{TiO}_{2}$ using the same experimental device as in the present work [18]. Despite the small improvement given by the treatment, there are still a number of factors that hinder the photocatalytic efficiency of the tested natural zeolites, most likely related to specific impurities. Therefore, better techniques of removal of these cations must be studied.

\section{CONCLUSIONS}

The Ethiopian natural zeolite sample (ET4) can be potentially used for photocatalytic applications. This sample contains other non-zeolitic phases like celadonite and ilmenite, which may synergize the potential application of this high Ti-content sample for photocatalysis. However, since it has large number of cations with appreciable amounts, complete removal of these cations is required to customize it to a photocatalyst.

\section{ACKNOWLEDGEMENTS}

Dr. Asfawossen Asrat and Prof. Solomon Tadesse, AAU, are deeply acknowledged for the geological work that allowed obtaining the natural zeolite samples. Dr. Raquel Garcia, Dr. Luis Gómez-Hortigüela and Prof. Joaquin Pérez-Pariente, CSIC, are also acknowledged for helpful discussions. ID is grateful to CSIC for her research leave at AAU. The authors acknowledge the Spanish Government, MINECO (projects MAT2012-31127 and CTM2012-34988) and the Spanish Research Council CSIC I-COOP- $\mathrm{H}_{2} \mathrm{O}$ (i-COOP014), for funding. The Chemistry Department, Addis Ababa University is also acknowledged for financial support.

\section{REFFERENCES}

1. Qu, Y.; Duan, X. Chem. Soc. Rev. 2012, 42, 2568.

2. Fujishima, A.; Honda, K. Nature 1972, 238, 37.

3. Tong, H.; Ouyang, S.; Bi, Y.; Umezawa, N.; Oshikiri, M.; Ye, J. Adv. Mater. 2012, 24, 229.

4. Asfaw, N.; Chebude, Y.; Ejigu, A.; Hurisso, B.B.; Licence, P.; Smith, R.L.; Tang, S.L.Y.; Poliakoff, M. Green Chem. 2011, 13, 1059.

5. Imamura, K.; Yoshikawa, T.; Hashimoto, K.; Kominami, H. Appl. Catal. B: Environ. 2013, 134, 193.

6. Khan, M.M.; Ansari, S.A.; Pradhan, D.; Ansari, M.O.; Han, D.H.; Lee, J.; Cho, M.H. J. Mater. Chem. 2014, A 2, 637.

7. Fresno, F.; Portela, R.; Suarez, S.; Coronado, J.M. J. Mater. Chem. 2014, A2, 2863.

8. Han, L.; Wang, P.; Dong, S. Nanoscale 2012, 4, 5814.

9. Zhang, N.; Zhang, Y.; Xu, Y.-J. Nanoscale 2012, 4, 5792.

10. Xiao, Q.; Gao, L. J. Alloys Compd. 2013, 551, 286.

11. Wang, C.; Shia, H.; Li, Y. Appl. Surf. Sci. 2011, 257, 6873.

12. Wang, C.; Shia, H.; Li, Y. Appl. Surf. Sci. 2012, 258, 4328.

13. Li, F.; Jiang, Y.; Yu, L.; Yang, Z.; Hou, T.; Sun, S. Appl. Surf. Sci. 2005, 252, 1410.

14. Pakrashi, S.; Jain, N.; Dalai, S.; Jayakumar, J.; Chandrasekaran, P.T.; Raichur, A.M.; Chandrasekaran, N.; Mukherjee, A. Plos One 2014, 9, e98828.

15. Gómez-Hortigüela, L.; Pérez-Pariente, J.; García, R.; Chebude, Y.; Díaz, I. Sep. Purif. Technol. 2013, 120, 224.

16. Mamo, W.; Awoke, Y.; Chebude, Y.; Díaz, I. Bull. Chem. Soc. Ethiop. 2015, 29, 95.

Bull. Chem. Soc. Ethiop. 2015, 29(3) 
17. Wise, W.S.; Colella, C. (Ed.) Handbook of Natural Zeolites, De Frede Editore: Naples; 2013.

18. López-Muñoz, M.J.; Revilla, A.; Alcalde, G. Catal. Today 2015, 240, 138. 